\title{
Ethylene Oxide-in-a-Bag Sterilization
}

National Cancer Institute

\section{Source}

National Cancer Institute. Ethylene Oxide-in-a-Bag Sterilization. NCI Thesaurus. Code C101692.

A sterilization process that uses ethylene oxide gas enclosed within a sealed bag to kill microorganisms. This process is typically carried out between 30 and 60 degrees $C$ and is applicable for use on small objects that cannot withstand high temperatures. 